\title{
A PRELIMINARY COMPARATIVE ANATOMICAL STUDY \\ OF THE MESOTHORACIC AORTA OF THE LEPIDOPTERA
}

$$
\text { by }
$$

John H. Hessel

A Thesis Submitted to the Faculty of the DEPARTMENT OF ENTOMOLOGY

In Partial Fulfillment of the Requirements For the Degree of MASTER OF SCIENCE In the Graduate College THE UNIVERSITY OF. ARIZONA 1966 
This thesis has been submitted in partial fulfiliment of requirements for an advanced degree at The Univensity of Arizona and is deposited in the University Library to be made available to borrowens under rules of the Library.

Brief quotations from this thesis are allowable without special permission, provided that accurate acknowledgment of source is made. Requests for permission for extended quotation from or reproduction of this manuscript in whole or in part may be granted by the head of the major department or the Dean of the Graduate College when in his judgment the proposed use of the material is in the interests of scholarship. In all other instances, however, permission must be obtained from the author.

SIGNED:

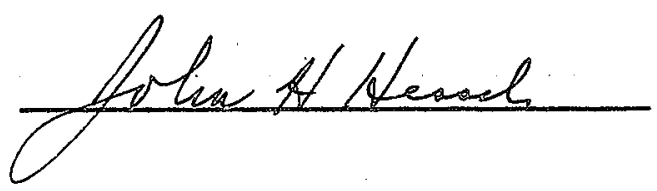

\section{APPROVAL BY THESIS DIRECTOR}

This thesis has been approved on the date shown below:
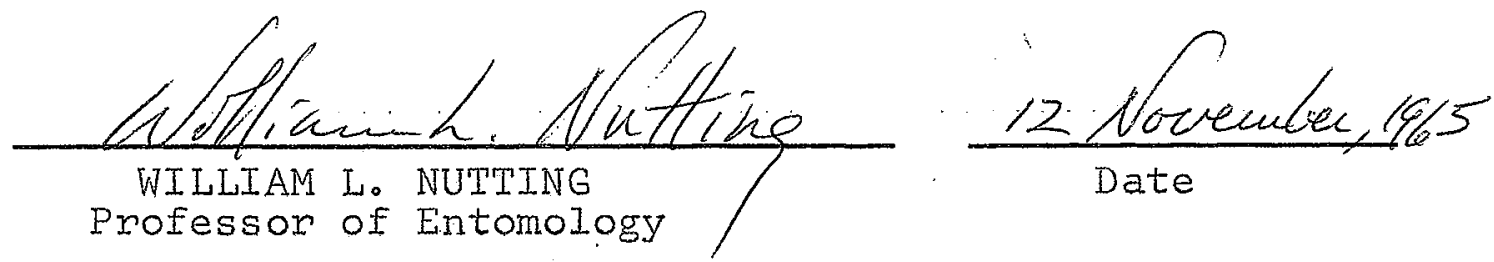


\section{ACKNOWLEDGMENTS}

For my introduction to the study of insect morphology as well as for his continued encouragement and most helpful suggestions throughout the course of this study, I wish to express my most sincere gratitude and appreciation to Dr. William L. Nutting。

To Dro Charles L. Remington of Yale University I am most grateful for his helpful suggestions concerning possible species for investigation and the communication of his current thoughts on the phylogeny of the Lepidoptera. In addition, I am most appreciative of Dr. Remington's kindness in supplying living specimens of Galleria mellonella for study.

Lastly, I am indebted to Mr. Scott ElIis of Hotchkiss, Colorado, for his efforts in supplying preserved specimens of Parriassius phoebis smintheus, and to my father, Sidney A. Hessel, for providing determinations of several of the species studied. 
TABLE OF CONTENTS

Page

LIST OF FIGURES

$\mathrm{v}$

ABSTRACT

vii

INTRODUCTION

LIST OF SPECIES OF LEPIDOPTERA STUDIED $\bullet \circ: 4$

MATERIALS AND METHODS 。. . . . . . 10

RESULTS $\quad 0.0 .0 .0 .0 \ldots \ldots \ldots$

Generalized morphology of the aorta . 14

Types of aortal arrangement 。. . 16

I. Ventral unchambered aorta . 16

2. Vertically chambered aorta 。 16

3. Horizontally chambered aorta. 18

Chamber 0.0018

Ostia 0.0 .019

Variations in the anatomy

of the chamber.... .22

Aortal configuration $\circ .24$

4. Donsal unchambered aorta... 26

Variations 0.0 .0 .26

PHYLOGENETIC CONSIDERATIONS AND CONCLUSIONS 。 28

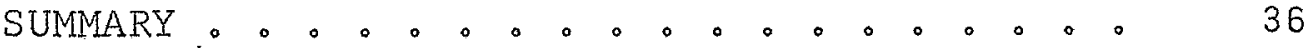

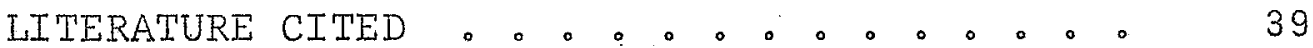

KEY TO ABBREVIATIONS 。. . 。. 。. . 41 
LIST OF FIGURES

Eigure

Page

I. Parasagittal view of portion of mesothorax showing typical rhopaloceran aortic and horizontal chamber location and configuration $\circ . \circ . \circ 42$

IA. Enlarged view of ostial apparatus 。 。 42

2. Parasagittal view of hjgher moth mesothorax showing aortic and vertical chamben location and configuration $a$

3. Parasagittal view of mesothorax of a pyraildoid showing primitive arrangement of the aorta $\circ .000 .0,0.0$

4. Parasagittal view of mesothorax of a cossoid showing aortal and chamber arrangement.

5. Parasagittal view of mesothorax of Megathymus yuccae.$\circ .0 .0 .0$

6. Parasagittal view of mesothorax of Hylephila phyleus

7. Parasagittal view of mesothorax of Epargyreus clarus $\circ \circ .0 .0 .0 .0$

8. Parasagittal view of mesothorax of Pyrrhopyge araxes $\circ .0^{\circ} \circ 0^{\circ} \circ 0^{\circ}$

9. Parasagittal view of mesothorax of Parnassius phioebus $\circ . \circ \circ \circ \circ \circ \circ$.

10. Parasagittal view of mesothorax of Battus philenor 
Figure

$\underline{\text { Page }}$

11. Parasagittal view of mesothorax of Papilio rutulus 0.0 .0 .0 .0

12. Parasagittal view of mesothorax of Papilio multicaudata $。 \circ .0 .0$

13. Parasagittal view of mesothorax of Pieris protodice . 0.0 .0$.

44

14. Parasagittal view of mesothorax of Colias caesonia

15. Parasagittal view of mesothorax of Danaus gilippus $0.0 \circ . \circ$.

16. Parasagittal view of mesothorax of Euptychia henshawi 0.0 .0$.

17. Parasagittal view of mesothorax of Vanessa cardui

18. Parasagittal view of mesothorax of Libytheana bachmanii .....。

19. Parasagittal view of mesothorax of Hypaurotis crysalus $\circ . .0$.

20. Parasagittal view of mesothorax of Apodernia mormo

21. Dendrogram showing general association of some lepidopteran superfamilies. 
ABSTRACT

The aortas of fifty-ejght species of

Lepidoptera representing two superfamilies of Rhopalocera and seven superfamilies of Heterocera were examined with the aid of vital staining. Two distinct types of mesothoracic aortal chambers were found. A vertical type was found in the Tortricoidea and higher moths, and a horizontal type was found in the Cossoidea and most rhopaloceran families. No chamber was found in the Papilionidae or Pyralidoidea. The former case may be attributed to a degenerate condition, and the latter to an exhibition of the primitive aortal configuration. A pair of lateral incurrent ostia of an unusual type were found in the horizontal chamber and the details of their conformation were worked out. It is proposed that the ostia operate passively in response to differential haemolymph pressure. In the Rhopalocera, the entrance of the aorta into the mesothorax is generally found to involve perforation of the second phragma. In the Hesperiinae, Papilioninae, and Lycaenidae the aorta passes beneath the phragma and enters the region 
viij.

of the flight muscles anterior to the phragma. Phylogenetic relationships based on chamber type are proposed which involve some modifications of previously proposed schenes. 


\section{INTRODUCTION}

While considerable work has been done relating to the external morphology of the Lepidoptera, little has been studied of the internal morphology in this order. The previous endeavors have been lapgely in the nature of more or less detailed studies of single species and, as far as I am aware, no comparative studies have been undertaken with the examination of representative species from various families and subfamilies.

Of all the intennal systems, the dorsal vessel probably has received the least attention. only in the case of Bombyz mori L。 has the insect been studied in detail, and the structure of the dorsal vessel of B. mori in all stages of the Iife cyele has been exhaustively treated by Gerould (1938), Brocher (1919, 1920) has dealt with the mesothoracic aorta in several species of Sphingidae. of all the Rhopalocera, only the monarch butterfly, Danaus plexippus ( $\left.L_{0}\right)$, has received significant treatment by internal morphologists, although Burgess (1880), Urquardt (1960), and 
Ehrlich and Davidson (196I) devoted little attention to the donsal vessel in thein respective studies of the internal anatomy of this well-known butterfly.

It was therefore decided that a comparative anatomical study of the dorsal vessel, such as was conducted by Nutting (195I) in the Orthopteroid Complex and Wille (1958) in the Apoidea, might yield hitherto undiscovered facts which would be useful to taxonomists and which might shed light on phylogenetic relationships within the Lepidoptera. In this "exploratory" study to determine whether a more exhaustive investigation would prove worth while, it was thought best to limit the investigation to the mesothoracic aorta of the Rhopalocera and to a few representative Heterocera which might reveal a close phylogenetic relationship to the Rhopalocera.

Species of Rhopalocera were chosen in an attempt to represent as many subfamilies as possible. The intensity of treatment of the subfamilies is, admittedly, uneven. This is due partially to a bias on the part of the author for common, Iarge, and easily dissected species, and partly due to the necessity of appraising the differences found. Only by investigating several closely related species could observed differences be 
ascribed to specific, generic, subfamily, or family characteristics. The reason for the relatively extensive treatment of the Papilioninae was due to the unusual nature of the aorta in this taxon. With the exception of the Parnassinae, representatives were collected by the author in Arizona or connecticut. For this reason subfamilies not represented in the fauna of these states regrettably have been omitted. 


\section{LIST OF SPECIES OF LEPIDOPTERA STUDIED}

In the following arrangement of species studied, no single authority is followed. Rather, the most readily available of recent synonymic lists are used for species and generic nomenclature, while the most generally accepted systematic schemes, which reflect recent revisionary studies are used for higher categories. This decision is based largely on convenience and is not intended to express any convictions of the author as to the systematics of the Lepidoptera.

In the Rhopalocera, nomenclature through the generic level in the Papilionoidea, and for all levels of the Hesperioidea follows Dos Passos (1964). Higher categories of the Papilionoidea are those of Ehrlich (1957)。 MeDunnough $(1938,1939)$ is followed through the generic level, and Remington (1954) is used for the higher classification of the Heterocera.

$$
\text { Although for convenience, subfamily, family, }
$$

and superfamily names are used in the text for discussion, extrapolation beyond the species listed is inadyisable。 
RHOPALOCERA

HESPERIOIDEA

Megathymidae

Megathyminae

Agathymus neumoegeni (Edwo)

Megathymus yuccae arizonae Tinkham

Megathymus streckeri texanus B。 $E$ McD。

Hesperiidae

Hesperiinae

Hylephila phyleus (Drury)

Copaeodes aurantiaca (Hewitson)

Pyrginae

Erynnis zarucco funeralis (Scudder \& Burgess)

Thorybes pylades (Scudder)

Epargyreus clarus (Cramer)

Pyrgus communis communis (Grote)

Pyrrhopyginae

Pyrrhopyge araxes arizonae (Godman \& Salvin)

PAPILIONOIDEA

Papilionidae

Parnassiinae

Parnassius phoebus smintheus Doubleday 
Papilioninae

Battus philenor (L)

Papilio polyxenes asterias Stoll-

Papilio cresphontes cramer

Papilio glaucus Lo

Papilio rutulus arizonensis Edw.

Papilio multicaudata (Peale MS) Kirby

Papilio troilus I.

Pieridae

Pierinae

Pieris protodice $B_{0}$ \& LeC. -

Pieris rapae (L.o)

Coliadinae

Colias eunytheme Bois.

Colias caesonia (Stoll)

Phoebis sennae eubule $\left(L_{0}\right)$

Eurema mexicana (Bois。)

Eurema niccipe (Cramer)

Nymphalidae

Danainae

Danaus plexippus ( $\mathrm{L}_{0}$ )

Danaus gilippus strigosus (Bates)

Satyrinae

Euptychia henshawi Edw。 
Euptychia rubricata Edw。

Gyrocheilus patrobas tritonia (Edw.)

Nymphalinae

Asterocampa leilia $\left(E d w_{0}\right)$

Limenitis astyanax arizonensis Edw.

Limenitis bredowii eulalia Doubleday

Vanessa cardui ( $\mathrm{L}_{0}$ )

Nymphalis antiopa ( $\left.L_{0}\right)$

Speyeria eybele (Fabro)

Euptoieta claudia (Cramer)

Agraulis vanillae ( $\left.L_{0}\right)$

Libytheidae

Libytheinae

Libytheana bachmanii (Kirtland)

Lycaenidae

Riodininae

Apodemia morme (Felder \& Felder)

Apodemia palmerii (Edw。)

Emesis: zela Butler

Lycaeninae

Hypaunotis enysalus (Edw.)

Atlides halesus. (Cramer)

Strymon melinus (Hübner) 
HETEROCERA

Cossoidea

Cossidae

Zeuzera pyrina ( $L_{0}$ )

Pyralidoidea

Pyralididae

Galleria mellonella (L。)

Tontricoidea

Tortricidae

Archips rosaceana (Harris)

Geometroidea

Thyatiridae

Pseudothyatira cymatophoroides (Gno)

Geometridae

Amphidasis cognataria Gn。

Bombycoidea

Saturniidae

Anisota rubicunda (Fabro)

Adelocephala heiligbrodti (Harvo).

Lasjocampidae

Malacosoma americana (Fabr。)

Sphingoidea

Sphingidae 
Sphinx gondius Cram.

Paonias exciecata ( $A_{0} \cdot \varepsilon S_{0}$ )

Celerio Iineata (Fabr.)

Noctuoidea

Noctuidae

Catocala ilia (Cramer)

Notodontidae

Nadata gibbosa (A。 E So)

Lymantriidae

Liparis dispar (I.) 
MATERIALS AND METHODS

In all but a few cases, a minimum of five specimens of each species of Rhopalocera was dissected. Usually, both sexes were examined. Except for the cossid, Zeuzena pyrina, only one on two specimens of each heteroceran species. were dissected. Therefore. it is only reasonable that findings related to the Rhopalocera. and Cossidae bear a higher neliability than findings related to the remainder of the Heterocera.

Specimens captured in the field were placed in glassine envelopes and temporanily stored alive in a refrigerator. If dissections could not be made within a day or two, storage of injected specimens in a freezer proved most satisfactory。 Specimens preserved by freezing are quite similar to fresh material.

If a freezer was not available, on freezing impractical, reasonably satisfactory specimens were obtained by preserving in $95 \%$ ethyl alcohol or Kahle's fluid after injection. In specimens preserved in this manner, the left wings were removed as close to the thorax as possible to facilitate penetration of the preservative。 
Since lateral dissections of living or fresh specimens were found to be the most satisfactory, the wings on the left side were excised and the specimen fastened to a wax-bottomed dissecting dish by securing the right wings by means of a \#4 insect pin with a \#0 insect pin partially wound on its axis and projecting at right angles. By inserting the $\# 4$ pin near the base of the costa of the forewing, the pressure exented by the \#0 pin on the sunface of the wings was sufficient to restrain all but the most robust species. When the specimen was securely fastened lying on its right side, the insect was flooded with sufficient insect Ringer solution to cover the thorax. The thorax was then opened under a binocular dissecting microscope, by carefully removing the integument and muscles from the left side until the aorta was exposed. In preparations made in this manner, the aorta was observed to remain active for as long as several hours. Occasional irrigation with fresh Ringer's often served to increase the activity of the aonta. Whether this was due to the effect of aeration or simple mechanical stimulation was not determined.

Early in the study it was found that vital staining with a saturated solution of trypan blue in 
insect Ringer's (Hershberger, 1948), greatly facilitated dissection. Injection was made through a ventral intersegmental membrane into the abdominal cavity using only sufficient material to cause very slight abdominal distention. The colored material was readily aspirated by the abdominal heart and carried forward to the mesothoracic aorta. Injection seemed to produce little trauma in the insect except in moribund specimens. It was found that a lapse of a few minutes was sufficient to produce adequate staining of the aorta and associated structures. However, dissection was often delayed overnight with no apparent ill effect to the injected insect.

In cases where only the gross anatomy of the aonta was under consideration, dissections were made under $95 \%$ ethyl alcohol rather than under Ringer's. Removal of muscles is greatly facilitated by this substitution since the muscle fibers lose their natural elasticity and readily separate from the integument. Unfortunately, the aorta of specimens killed by immersion in alcohol often presents a somewhat distorted appearance. The alcohol apparently causes the collapse and considerable shrinking of the delicate muscular aorta and certain fine details may be obscured. In addition, the air 
present in fresh tracheal material is readily replaced by alcohol and these structures tend to collapse and take on the appearance of membranous films.

Drawings were made by taking photomicnographs of the specimens with a $35 \mathrm{~mm}$. single lens reflex camera and High Speed Ektachrome Type B film。 The slides obtained were then projected to the desired size and the drawings made by tracing. By using this method, drawings of very high reliability could be obtained with a minimum of effort and artistic technique. 


\section{RESULTS}

The mesothoracic aortal arrangement in the Lepidoptera consists of four principal types with some minor variations. These types are 1) a simple ventral tube running from the abdominal heart to the head, 2) an arrangement including a donsal vertical chamber, 3) an arrangement which includes a dorsal horizontal chamber, and 4) a donsal unchambered aorta.

\section{Generalized morphology of the aorta}

The aorta, except for the chamber, is a nearly transparent, unosteolated tube composed of a single layer of obliquely oriented muscle fibers. It has numerous tracheal branches associated with it but not necessarily attached to ito The tracheal material appears to serve as the primary device for fixing the position of the aorta in the mesothorax. In several specimens strands of connective tissue or trabeculae connect the recurrent-horizontal aortal segment (see below) to the horizontal chamber. 
In live preparations of Rhopalocera the aorta (and chamber when present) was observed to undergo peristaltic contractions. The beat of the aorta is considerably slower than that of the abdominal heart. This asynchrony of beat would seem to imply actual independent contraction of the aorta rather than a passive expression of varying blood volume supplied from the abdomen. The aorta was also observed to contract asynchronously with the mesothoracic chamber. Instances were even observed where the aorta continued to pulsate after the chamber had ceased contracting. In these cases, it should be recognized that the insect had been subjected to considerable trauma, and no implications should be drawn as to normal behavion in the intact insect. Periodic heartbeat reversal, a phenomenon often recorded in insect cardiac Iiterature, was frequently encountered. This also may have been caused by trauma induced during dissection. No direct innervation of aorta on chamber was ever detected, despite several patient attempts to trace mesothoracic nerves. 
Types of aortal arrangement

1. Ventral unchambered aorta

The simplest aortal arrangement encountered in the Lepidoptera was found in the Pyralidoidea (Fig. 3). It consists of a straight, unosteolated ventral tube (AO) attached to the esophagus and running "dorsal to that structure through the mesothorax. At no point does it rise into the region of the flight muscles. No trace of chamber, trabeculae, on pericardial cells was observed. The above arrangement, similar to that encountered in representatives of the Neuroptena, Trichoptera, and Mecoptera, which were examined supenficially during this study, probably exemplifies the "primitive" condition of the aorta in the Lepidoptera.

2. Vertically chambered aorta

The vertical chamber and the aortic arrangement associated with it was first described by Brocher (1919) in the Sphingidae. It was found in all species examined from the Tortricoidea, Geometroidea, Bornbycoidea, Sphingoidea, and Noctuoidea. For convenience, the last four of these superfamilies will hereafter be referred to as the "higher" moths. 
The vertical chamber is an erect, club-shaped sac, with ascending and descending aortic branches (Fig。 2, A å and $\underline{D}$ a.o) which may or may not adhere to each other. The chamber is provided with a pair of donsal

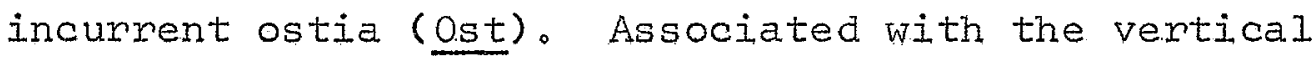
chamber, there is also present a contractile muscular sheet ( $\mathrm{Dph}$ ) located beneath the mesothoracic scutellum $\left(\underline{\mathrm{Scl}}_{2}\right)$. This subscutellar diaphragm serves to direct the flow of haemolymph anterionly. to the ostial region of the chamber (Brocher, 1919; Gerould, 1938)。 The chamber itself is supported and attached to the notum in the region of the scuto-scutellar suture (vs) by trabeculae (Tr). The details of the chamber and accessory diaphragm were adequately described by Gerould (193.8) and will not be further dealt with here.

Differences in the arrangement of the ascending and descending aortic branches of the vertical chamber were obsenved. However, since the number of species of Tortricoidea and higher moths was so limited, it is considered inadvisable to discuss the comparative anatomy of the aorta in these groups at this time. It is anticipated that this will be the subject of a subsequent paper. 
3. Horizontally chambered aonta

Chamber

The horizontal chamber was first described by Burgess (1880) in Danaus plexippus (=anchippus). It was found in all species examined from the Cossoidea, Hesperioidea, and Papilionoidea except the Papilionidae.

The horizontal chamber consists of a large, muscular structure oriented antero-posteriorly. It is situated ventrad of the scutum and scutellum (Fig。 I, $\underline{S c t}_{2}$ and $\underline{S c I}_{2}$ ) and occupies a position immediately between and above the most dorsal pain of dorsallongitudinal flight muscles. The chamber is supported by trabeculae (Tr) which run from the chamber to the integument, the flight muscles, the sheet of trachael material located between the integument and the chamber and, in some cases, the recurrent-horizontal segment of the aorta ( $\mathrm{Rh}$ aor).

The trabeculae may well be the vestiges of mesothoracic alary muscles. Especially in the cossid Zeuzera pyrina, the shape and arrangement is strongly suggestive of alary muscles. However, pericardial cells which are usually associated with alary muscles were not observed. 
Ostia

The horizontal chamber was always found to bear a pair of lateral incurrent ostia (Fig。 IA)。The supporting and associated structures of these ostia are distinct from those of the dorsal ostia of the ventical chamber, and appear to represent an arrangement unique among the insectan hearts. The ostia were not noted by Burgess (1880) or Urquhart (1960)。 Ehrlich and Davidson (1961) observed the supporting structures but failed to recognize thein significance. They stated that "there appears to be a pair of round lateral openings (or thin areas) in the aortal chamber."

While the gross appearance of the ostial apparatus is that of a "porthole, it actually consists of two thickened edges of chamber wall and a delicate membrane essentially parabolic in shape (Fig。IA, Mb)。The vertex of this parabolic membrane is posterior, and the vertex and arms are attached to a thickened edge of the chamber wall. A free concave edge of the membrane (IIP) connects the arms of the parabola and lies mesad of the thickened anterior free edge of the chamber wall ( $01 \mathrm{p}$ ). The lips of the ostium proper are thus formed by the membrane and the chamber wall. 
Although there is considenable overlap of membrane and chamber wall at the dorsal and ventral extremes of the free edge, very little overlap occurs near the midline as the concave margin of the membrane approaches tangency with the edge of the chamber wall. Despite considerable bulging of the membrane during systole, leaks were seldom observed and the seal appears to be quite tight。

The configuration of the ostial apparatus suggests the somewhat inelegant analogy to an open fly of a pair of pants. The outer, left edge of the fly represents the anterior thickened edge of the chamber wall, and the inner, right edge of the fly represents the posterior thickened edge of the chamber wall to which the membrane is attached.

During extended observations of live heart preparations material was never seen to enter the chamber. I propose that the ostia operate passively in response to differential haemolymph pressure in some such manner as follows. The fluctuations in thoracic blood pressure external to the chamber are due to alternate contractions of the tergo-sternal and the dorsal-longitudinal flight muscles which change the volume of the thorax. Pressure within the chamber is controlled by the systole and 
diastole of the chamber itself. When the chamber is in the diastolic phase and the tergo-stemal muscles contract, the external pressure exceeds the internal pressure and haemolymph is forced into the chamber as the membrane is pushed inward away from the chamber wall. When the chamber enters systole, the internal pressure increases and forces the membrane against the chamber wall forming a tight seal.

If this interpretation is correct, it explains Why the ostia: were never obsenved to function. By opening the thorax during preparation, it was rendered impossible for the external pressure to surpass the internal pressure of the chamber. Direct observation of the chamber in the intact thorax was not possible. Unlike the almost transparent integument of the higher moths, the Papilionoidea and most of the Hesperioidea possess a melanized, opaque thoracic integument, and the subnotal sheet of tracheal material and the lateral location of the ostia in the chamber made observation in those species of Hesperioidea with transparent integuments equally impossible.

The chamber probably functions as an aid in circulating the blood bathing the flight muscles during their activity. The advantage of such a system is 
obvious. It provides prompt removal of metabolic waste products from the immediate site of the flight muscles and serves to increase the over-all rate of the circulation in the insect duning flight. However, this arrangement restricting ostial function to flight periods seems decidedly inferion to that in the Tortricoidea and higher moths in which the contraction of the accessory musculan diaphragm allows operation of the ostia during rest periods as well as flight periods。 It is possible that the wing flexing behavior of some Nymphalidae may be an adaptation which allows the chamber to function in removing haemolymph from the mesothorax duning non-flight periods.

\section{Variations in the anatomy of the chamber}

In those Rhopalocera which possess a chamber, no distinct interfamilial differences in the anatomy of the chamber were discerned. When a reasonably long series of specimens was compared, characteristics which seemed to be present tended to break down. Even the relative location of the lateral ostia, which were found in all horizontal chambers, tended to be variable within a species. Although the following generalizations appear to be valid based on the few species examined, it is 
entirely possible that if more species had been studied, even the following statements might prove invalid. It should be kept in mind that the figures are based on single specimens, and since there may be no such entity as a "typical" example, extrapolation beyond these individuals is probably inadvisable.

In the Pieridae (especially in the Coliadinae) the chamber appears to be somewhat more spherical than in the other families of Rhopalocera (Figs。 13, 14)。 The Hesperioidea (Figs。 5-8) and Lycaenidae (Figs。19, 20) generally possess a relatively long, narrow chamber and in the former the anterion portion is acutely angled. The chamber in the Nymphalidae (Figs。 15-17) and Libytheidae (Fig。18) tends to be intermediate in shape.

The chamber found in the Cossidae (Fig。 4), although unmistakably of the horizontal type, is distinct. The chamber in this family lies significantly posterior to that in the Rhopalocera, being situated, for the most part, beneath the scutellum rather than extending anteriorly beneath the scutum. In addition, the anterior part of the chamber bends ventrally away from the notum nather than remaining horizontal throughout its length as in the Rhopalocera. 


\section{Aortal configuration}

After entering the mesothorax ventrally the aorta runs dorsad, anterior and more or less parallel to the second phragma (Fig。 I, $2 \underline{\mathrm{Ph}}$ )。 This ascending aontal segment (A ao) joins the posterior part of the horizontal chamber. When the aorta leaves the anterior region of the chamber, it bends sharply ventrad for a short distance and then parallels the long axis of the chamber as it travels posteriorly. This segment of the aorta is here temed the recurrent-horizontal aontal segment ( $\underline{R h}$ ao). It then turns sharply ventrad as it approaches the ascending aorta and parallels the latter, adhering to it for a variable distance. This descending aontal segment ( $D$ ao) then bends sharply anteriorly and the anterior aortal segment (Ant ao) travels anteroventrally until it attaches to the esophagus, and passes cephalad.

\section{Variations}

The above description appears to hold true for all the families of Rhopalocena which possess a chamber. Relative diameters of the aortal segments appear to be 
intraspecific variables and not to constitute useful characters as used by Burgess (18.81)。

The point at which the aonta enters the mesothorax shows some variation between different groups. In the Hesperioidea (except for the Hesperiinae) and in the Pieridae, Nymphalidae, and Libytheidae the aorta enters the mesothorax through a notch or perforation in the ventral portion of the second phragma. In the Lycaenidae and Hesperiinae (Figs, 6, 19, 20) it passes beneath the phragma and enters immediately anterior to it. The arrangement of the aorta in the cossidae (Fig。 4) bears special mention, since two striking contrasts to the rhopaloceran type of arrangement occur. The point at which the aorta enters the mesothorax is most unusual. The second phragma is perforated by the aorta near its dorso-ventral midpoint, nather than near its most ventral portion. In addition the aorta, after leaving the anterior portion of the chamber, travels antero-ventrally without recurving posteriorly. Since Zeuzera pyrina was the only species of Cossidae examined, it is not possible to state at this time whether these charactens will hold true for the family。 
4. Dorsal unchambered aorta

In the Papilionidae (Figs, 9-12) no chamber is present. The aorta rises into the region of the flight muscles in a manner generally similar to that in other families of Rhopalocera. No ostia on trabeculae were observed and the mesothoracic aorta appears to be uniformly composed of a single layer of obliquely oriented muscle fibers throughout its entire length. Its position appears to be fixed by tracheal branches which encircle it.

$\underline{\text { Variations }}$

In the Parnassinae (Fig。9) the aorta enters the mesothorax through a notch in the second phragma much as in all rhopaloceran taxa except the Lycaenidae and Hesperiinae. The aortal pathway forms a smooth curve rising at its apex to the mid-region of the dorsal Iongitudinal flight muscles before tuming ventrad and passing beneath the first phragma.

In the Papilioninae (Figs。 10-12) the aorta passes beneath the second phragma and enters the region of the flight muscles well anterior to that integumental structure, almost reaching the funca before turning 
dorsad. From this point, no description seems meaningful. A fantastic array of anomalies is presented by this subfamily and intraspecific variation is so extensive that it is difficult to find two specimens alike. While the figures represent three species, the three confornations shown might have been taken from representatives of a single species, and the figures should not be taken as typifying the species. involved. 
PHYLOGENETIC CONSIDERATIONS AND CONCLUSIONS

An attempt to determine close phylogenetic relationships based on a single character such as the morphology of the mesothoracic aorta is risky at best and unjustifiable at worst. However, certain broad relationships among taxa can be inferred from the common possession of a particular structure. Therefore it is felt that there is some justification for making certain modifications of the most generally accepted phylogenetic schemes on the basis of companative aortal morphology. In reaching the following conclusions only the most stable and obvious character, that of chamber type, has been utilized.

Forbes (1.923) stated that the Papilionidae are the most primitive of the Papilionoidea, tracing their Iineage through the Hesperioidea to give rise directly to the Pieridae. Zeuner (1960), on the basis of wing venation and tracheation, also considered the Papilionidae to be the most primitive papilionid family。 Brown (1956) concurred regarding the primitive nature of the Papilionidae based on the hesperioid-like larva. of Parnassius. In contrast, Ehrlich (1957) stated that 
the Papilionidae actually possess". - significantly more characters in their specialized state than the other four families" (of Papilionoidea)。

The apparent disagreement between Forbes, Zeuner, and Brown and Ehrlich may be largely semantic. The term "primitive" is unfortunate since it is not always clear whether it is used in a spatial on temporal sense. The retention of the primitive larval condition and wing venation in the Papilionidae would seem to indicate that the papilionid phyletic branch has its base at a lowen point in time than the branches leading to the other papilionoid families. However, the possession of a significantly, greater number of specialized characters would seem to indicate that the Papilionidae are spatially the most advanced family.

If Forbes, Zeuner, and Brown referred to the point in time where the Protopapilionidae split off, then they may be quite correct in their decisions that the Papilionidae are the most primitive of the Papilionoidea. However, if they used the term primitive in a spatial sense, the utilization of only one or two subjectively chosen characters apparently has led to an exroneous conclusion. 
Since all existing forms of life have had the same length of time in which to evolve, tracing their Iineage ultimately to the origin of life, the spatial location of taxa is presumably due to differences in evolutionary rates. If variability is considered as an indication of evolutionary rate then, insofar as the aorta is concenned, the Papilionidae (especially the Papilioninae) might suggest tachytelic evolution.

Forbes" idea of deriving one extant taxon "through" anothen is perhaps not a thoroughly sound approach. Howeven, this position will be taken as a basis for discussion. Considering the lack of a horizontal aontal chamber, it is not likely that the Papilionidae, as they exist at this time, could have given rise to the Pieridae since both the Hesperioidea and the Pieridae possess well-developed horizontal chambers. Barring the unlikely phenomenon of convergent evolution of such a chamber in these two groups, the Papilionidae must be considered to represent the end of an evolutionary line. Unfortunately, the findings of this study do not permit the temporal placement of the base of the papilionid branch。

The decision to consider the dorsal unchambered aorta of the Papilionidae as exemplifying evolutionary 
degeneration of the horizontal chamber would be highly subjective if based solely on aontal morphology. If one considers the Papilionid aortal pattern to be intermediate between the primitive ventral arrangement of the Pynalidoidea and the dorsal horizontally chambered aorta of the Cossoidea, Hesperioidea, and remaining families of Papilionoidea, then the Papilionidae would necessarily be derived from a phyletic branch having its base below that of the Cossoidea. Such a disconcerting arrangement would be indefensible on the basis of other morphological characters which the Papilionidae share with the remaining papilionoid families. Therefore, there appears to be no reasonable alternative to considering the papilionid aorta as exhibiting evolutionary degeneration of the chamber, and hence it is clearly in a more "advanced" state than in any other papilionoid family.

The lack of a chamber in the Parnassiinae and Papilioninae would make examination of Baronia brevicornis Salvin, of the monotypie subfamily Baroniinae, of intense interest. There appears to exist a general agreement that the phyletic separation of the Baroniinae substantially preceded the phyletic separation of the other two subfamilies (Ehrlich, 1958; Munroe, I96I; Munroe and Ehrlich, 1960)。 Unfortunately, no specimens of $\underline{B}$. brevicornis were available for examination and the 
discovery of whether this species possesses a chamber will have to await the availability of specimens. Although the aorta fails to perforate the second phragma before rising to the region of the flight muscles in the Hesperiinae, Lycaenidae, and Papilioninae it seems unwise to attach any phylogenetic significance to this trait. Any attempt to relate these three taxa on the basis of this character produces a phylogenetic arrangement so at variance with any accepted scheme that it would seem that the pattern of aortal entrance into the mesothorax has evolved independently in the three groups. Of the superfamilies of Heterocera from which representatives were examined, only the cossoidea show a horizontal mesothoracic chamber of the type found in the Rhopalocera. All others either possess a ventical chamber or lack a chamber. It would seem proper, then, that the Cossoidea be placed on a side branch of the stem leading to the Rhopalocera. This arrangement is in agreement with Forbes (1923) and with Remington's curpent thinking (1965)。

The placement of the Tortricoidea and Pyralidoidea is not so simple and involves several rather subjective deqisions. Forbes (1923) derived the Cossoidea from the Tortricoidea and placed the latter on the main stem leading from the Tineoidea to the 
Cossoidea. If this decision is correct, then one would tend to conclude that the horizontal chamber was derived from the vertical chamber of the Tortricoidea. According to Remington (1965), the Cossoidea, Pyralidoidea, and Tortricoidea all split off the main stem leading to the highen moths at about the same time. If this decision is correct, one is led to the conclusion that the horizontal chamber of the Cossoidea evolved independently of the vertical chamber on both types evolved from a hypothetical prototype chamber.

Since the Pyralidoidea apparently lack a chamber of any sort, their placement by Forbes (1.923) on a branch leading to the higher moths above the branch leading to the Tortricoidea would seem to be in error unless the Pyralidoidea represent an instance of degeneration of the chamber such as is found in the Papilionidae. Since the aorta does not ascend into the region of the flight muscles it seems more likely that the Pynalidoidea possess the primary ancestral arrangement of the aorta, i.e. a straight ventral tube running from the abdominal heant to the head donsal to the esophagus. The absence of a chamber in the Pyralidoidea and the presence of a chamber in the other two superfamilies lead to a rejection of the concept of simultaneous phyletic 
branching of the Pyralidoidea, Tortricoidea, and Cossoidea.

It should be mentioned that Burgess (1881)

failed to note a chamber in the olethreutid, Rhyacionia ( $=$ Retinia) frustrana Comstk. This species was not examined in this study but a small chamber was found in the tortricid, Archips rosaceana. One is led to suspect that Burgess failed to observe the small, inconspicuous, nodular chamber and the associated subscutellan diaphragm. The pathway of the aorta is the same in both species of Tortricoidea as judged from Burgess' figure.

It is felt that, since the Tontricoidea do possess a vertical chamber and associated subscutellap diaphragm, they represent an offshoot from the main stem leading to the higher moths. Since they lack a chamber and the aorta follows a primitive ventral pathway, the Pyralidoidea probably represent an offshoot of significantly earlien onigin. The offshoot leading to the Cossoidea would then have its base located at a point between the two.

The placement of the Castnioidea can not be attempted at this time. This superfamily is generally accepted as occupying a position somewhere on the Cossoidea-Rhopalocera stem。 Unfortunately, no specimens 
of this taxon were available for study and its inclusion in this discussion is therefore impossible. Aware of the perils inherent in construeting a dendrogram based on the examination of so few representatives of the various superfamilies, as well as the obvious omission of so many of the primitive superfamilies from this study, the arrangement shown in Fig. 21 is tentatively proposed. The organization is intended to show only the most general relationships and associations and no precise spatial or temporal inferences should be drawn。 
SUMMARY

A preliminary study of the comparative anatomy of the rnesothoracic aorta of the Lepidoptera was undertaken to detemine whether such a study might shed light on phylogenetic relationships within the order and to work out certain morphological details of the aortal chamber. The sunvey includes nembers from four subfamilies of Hesperioidea, ten subfamilies of Papilionoidea, and eleven families from seven superfamilies of Heterocera. Altogether, the aorta and associated structures of fifty-eight species of Lepidoptera were studied with the aid of vital staining techniques.

Two distinct types of aortal chambers were observed. A vertical type with dorsal incurrent ostia and an associated accessory diaphragm was found in members of the Tortricoidea, Geometroidea, Bombycoidea, Sphingoidea, and Noctuoidea, A horizontal type with lateral incurrent ostia was found in the cossoidea, Hesperioidea, and Papilionoidea. In addition, it was found that no chamber exists in the Pyralidoidea or in 
the Papilionidae. The formen presumably exhibit the primitive condition of the aorta while the latter probably represents an instance of degeneration of the chamber.

The site of entrance of the aorta into the mesothorax was found to vary between some of the families and subfamilies. The usual entrance in the Rhopalocera was through the most ventral portion of the second phragma. However, in the Hesperiinae, Lycaenidae, and Papilioninae the phragma was not perforated by the aorta and entrance into the region of the flight muscles originated anterior to the phragma. In the Cossoidea, the phragma was perforated near its dorsoventral midpoint.

In those Rhopalocera which possess a chamber, the arrangement of the aorta into ascending, recurrenthorizontal, descending, and anterion segments was found to be constant. The Cossoidea lack a recurrenthorizontal segment and hence the descending aortal segment does not approach the ascending segment. In the Papilioninae the aortal arrangement is so variable as to defy generalization.

The details of the ostial configuration and structure were worked out and appear to represent a 
unique arrangement consisting of a thin membrane acting as the movable lip and the chamber wall acting as a fixed Iip. The passive operation of the ostia in response to differential haemolymph pressure is proposed as the governing principle behind the functioning of the ostia. Based on the type of chamber present, on the absence of a chamber, the following phylogenetic conclusions are proposed:

1. The Pyralidoidea represent a branch of significantly earlien origin than the Tortricoidea and Cossoidea。

2. The Tortricoidea represent an offshoot of the main stem leading to the higher moths.

3. The base of the Cossoidea Iine is located between those of the Pyralidoidea and Tortricoidea. 4. The Rhopalocera lie on the same stem as the Cossoidea.

5. The Papilionidae probably represent the most advanced condition of the rhopaloceran aorta. 


\section{LITERATURE CITED}

Brocher, F。 1919. Les organes pulsatiles méso- et métatergaux des Lépidoptêres. Archs。Zool. Exp。Gén。 T 58:149-171。

1920. Etude expérimentale sur le functionnement du vaisseau dorsal et sur la circulation du sang chez les insectes. 3me Partie. Le Sphinx convolvuli. Archș. Zool. Exp。Gén。 T 60:1-45.

Brown, F。M. 1956, Colorado butterflies, Part IV. Denver Mus。 Nat。 Hist, Proc。No。6, p. 235.

Burgess, E。 1880. Contributions to the anatomy of the milkweed butterfly (Danaus archippus Fabr。)。 50 th Anniv。 Mem. Boston Soc. Nat。 Hist. 16 pp.

1881. Note on the aorta of lepjdopterous insects. Proc. Boston Soc。 Nat。 Hist。 21:153-156。

Dos Passos, CoF。 1964. A synonymic list of the Nearctic Rhopalocena. The Lepid Soc. Mem。 No. I, New Haven, Conn。 145 pp。

Ehrlich, Po Ro 195.7. The higher systematics of the butterflies. J.Lepid, Soc。 11:103-106.

Ehrlich, P。 R。 and S。E. Davidson, 196I. The internal anatomy of the monarch butterfly, Danaus plexippus L。 (Lepidoptera: Nymphalidae). Microentomology $24: 85-133$ 。

Forbes, W。T.M. 1923. The Lepidoptera of New York and neighboring states。 Connell Univ。Agx。Exp。 Sta. Mem。68.

Gerould, J.H. 1938. Structure and action of the heart of Bombyx mori and other insects. Acta Zool.

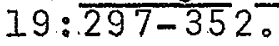


Hershberger, $R$ 。 V 1948 . Stain combinations in living insects。 Ohio J.Sci.48:16:1-168。

McDunnough, Jo 1938. Check list of the Lepidoptera of Canada and the United States of America. Part 1, Macrolepidoptera. Mem。South, Calif。Acad. Sci. Vol. I. $272 \mathrm{pP}$ 。

1939. Check list of the Lepidoptera of Canada and the United States of America. Part II, Microlepidoptera. Mem. South. Calif。Acad.Sci. Vo1.2, No. 1. 171 pp。

Munroe, E. 1961. The generic classification of the Papilionidae, Can. Entomol。, Supplement 17. 51 pp.

Munroe, $E_{0}$ and $P, R$. Ehrlich, 1960。 Harmonization of concepts of higher classification of the Papilionidae。 J. Lepid。Soc。 14:169-175。

Nutting, W。 Lo 19.51. A comparative anatomical study of the heart and accessory structures of the orthopteroid insects. J。 Monphol. 89:501-597.

Remington, C. L。 1954。 in Co To Brues, A。 Lo Melander, F. M. Carpenter, Classification of insects. Bull. Mus, Comp。Zoöl。 Harv。 108:226-305。

1965. Personal communication.

Unquhart, F. A. 1960. The monarch butterfly. Univ。 of Toronto Press, Toronto, Canada. p. 250 .

Wille, A. 1958. A comparative study of the donsal vessel of bees. Ann. Entomol. Soc.Amer. 51:538-546.

Zeuner, F。 E. 1960. Notes on the evolution of the Rhopalocera (Lep。)。XI Int。Kongr。 Entomol。, Verh., Band I Sektion I bis VI: 310-313。 
KEY TO ABBREVIATIONS

A ao

Ao

Ant 2.0

$\mathrm{Ch}$

$D$ ao

Dph

IIP

Mb

Olp

Ost

Ost ap

$2^{\mathrm{Ph}}$

$\mathrm{Rh}$ ao

$\mathrm{SCl}_{2}$

$\operatorname{set}_{2}$

$\operatorname{set}_{3}$

$\operatorname{Tr}$

vs
Ascending aortal segment aorta

anterion aortal segment

chamber

descending aortal segment

subscutellax diaphragm

inner ostial Iip

membrane

outer ostial lip

ostium

ostial apparatus

second phragma

recurrent-horizontal aortal segment

mesothoracic scutellum

mesothoracic scutum

metathoracic scutum

trabeculae

scuto-scutellar suture 


\section{EXPLANATION OF FIGURES}

Fig. I Parasagittal view of portion of mesothorax showing typical rhopaloceran aortic and horizontal chamber location and configuration.

Fig。 IA Enlanged view of ostial apparatus.

Fig. 2 Parasagittal view of higher moth aortic and vertical chamber location and configuration.

Fig. 3 Parasagittal view of mesothorax of a pyralidoid showing primitive arrangement of the aorta.

Fig. 4. Parasagittal view of mesothorax of a cossoid showing aortal and chamber arrangement. 

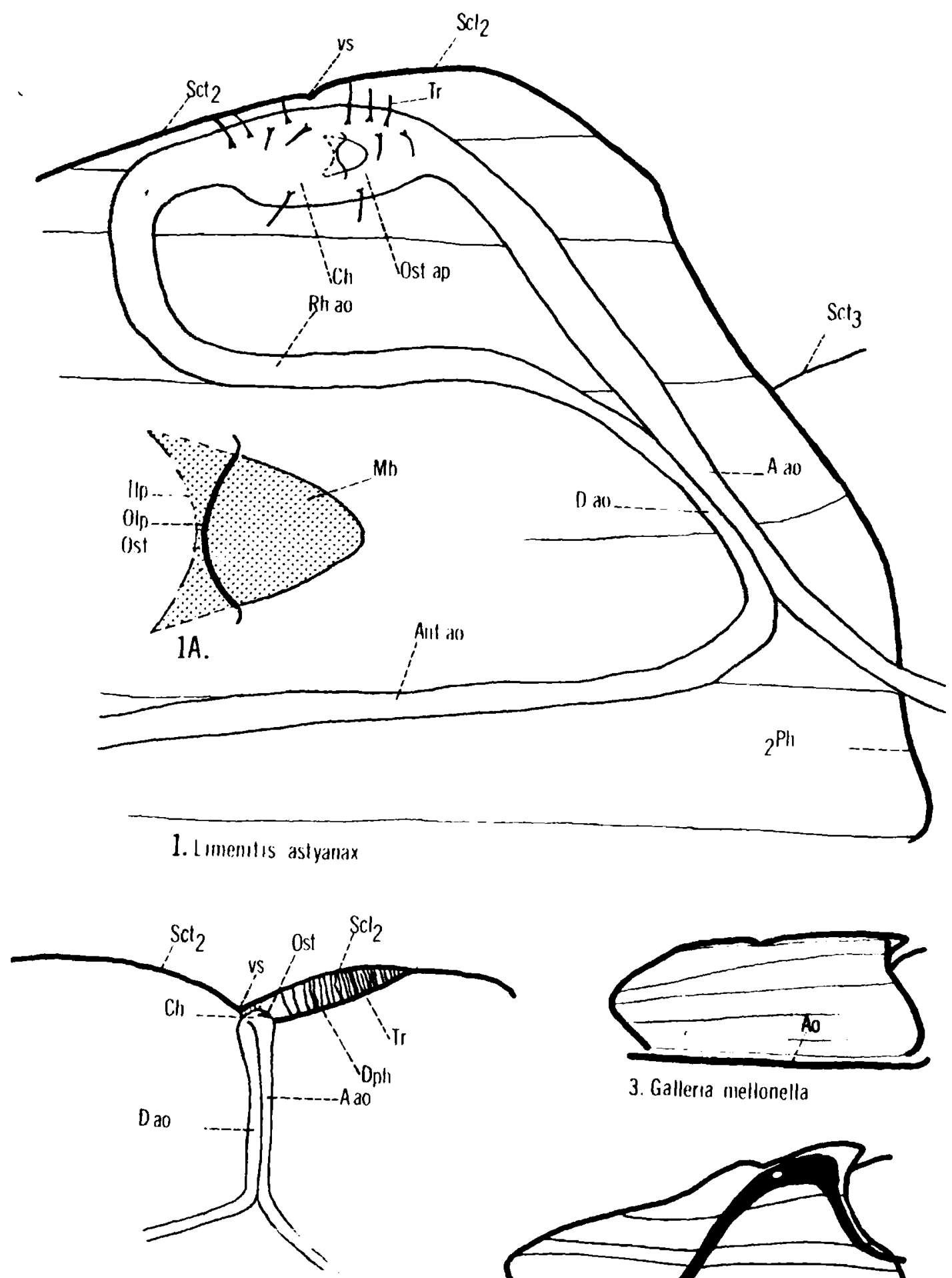

2. Celerio lineata

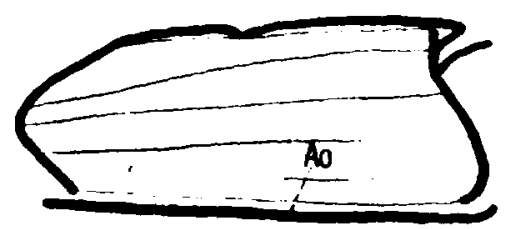

3. Galleria mellonella

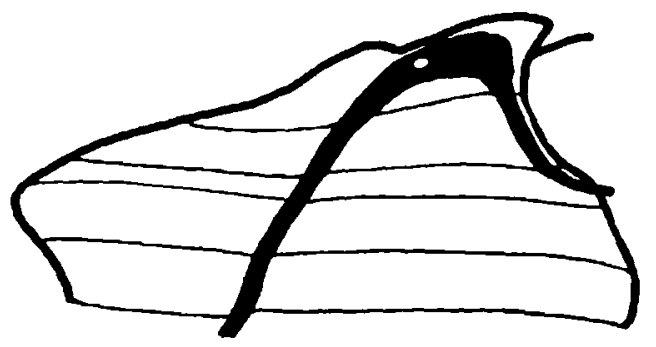

4. Zeuzera pyrina 

EXPLANATION OF FIGURES
Figs. 5-12 Parasagittal views of meso- thoraces of indicated species showing aortal and chamber arrangement. The following rhopaloceran subfamilies are represented:

Fig。 5 Megathyminae

Fig. 6 Hesperitinae

Fịg. 7 Pyrginae

Fig. 8 Pyrrhopyginae

Fig. 9 Parnassiinae

Figs. 10-12 Papilioninae 


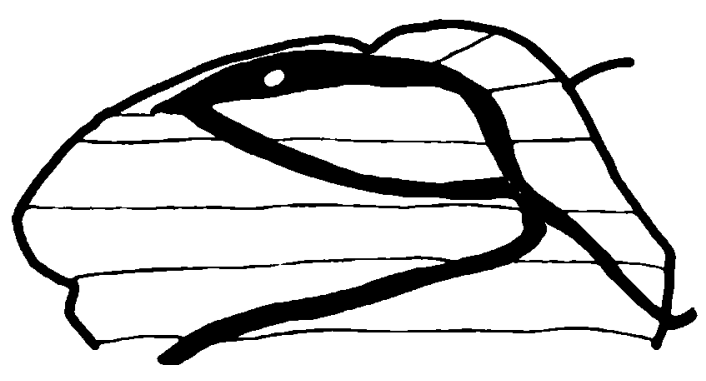

5. Megathymus yuccae

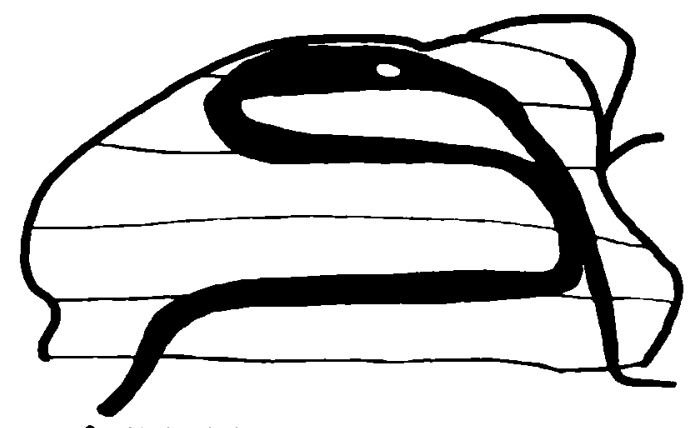

6. Hylephila phyleus

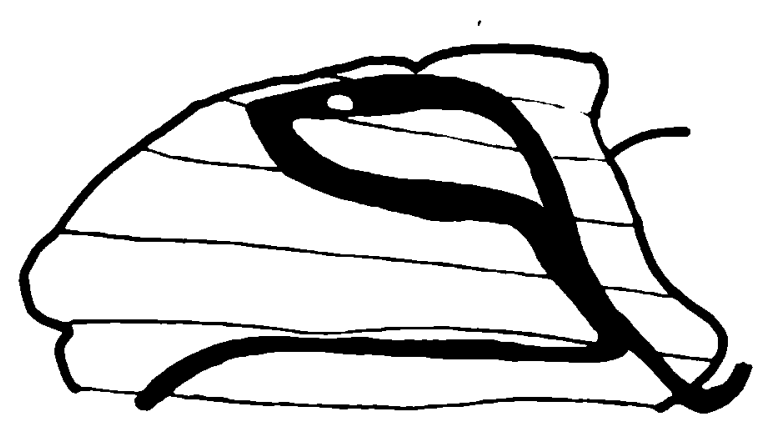

7. Epargyreus clarus

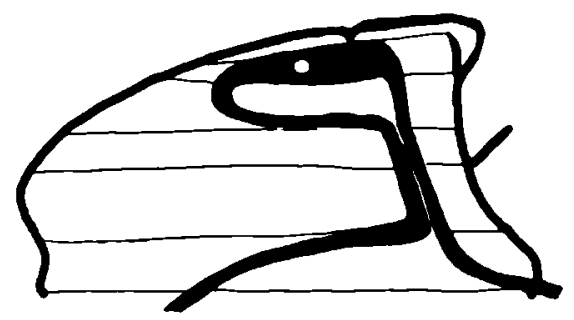

8. Pyrrhopyge araxes
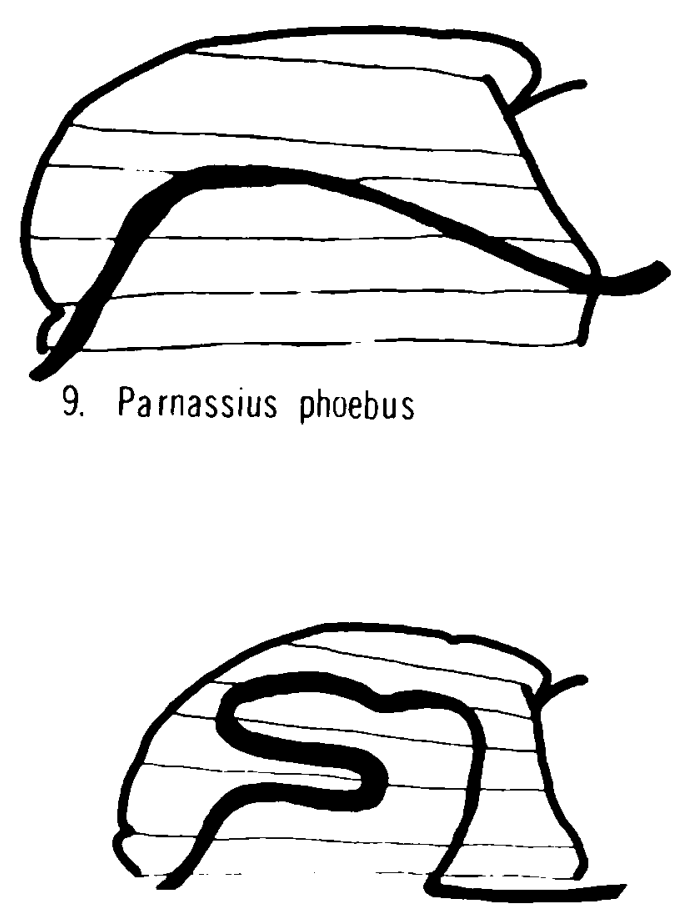

10. Battus philenor

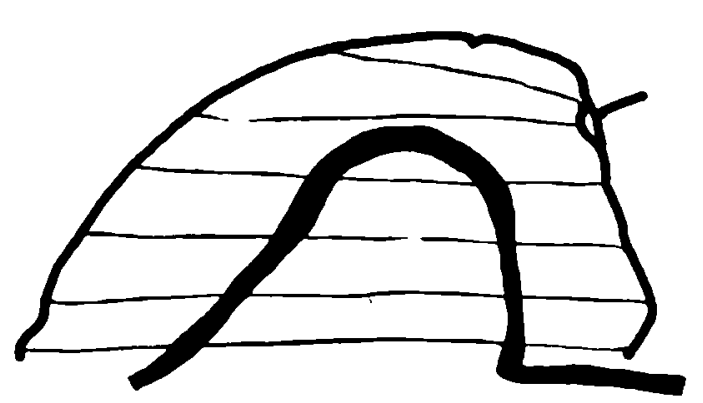

11. Papilio rutulus

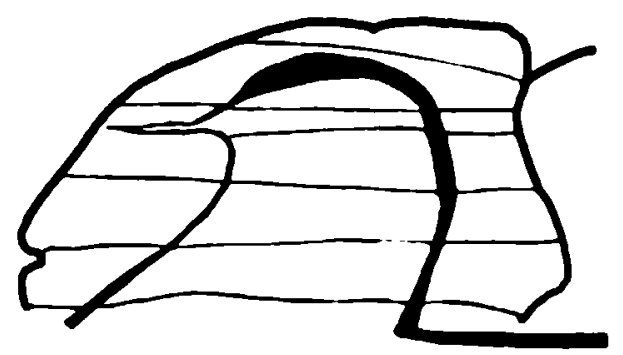

12. Papilio multicaudata 



\section{EXPLANATION OF FIGURES}

Figs。 $13-20$

Parasagittal views of mesothoraces of indicated species showing aortal and chamber arrangement. The following rhopaloceran subfanilies ane represented:

Fig. 13 Pierinae

Fig. 14 Coliadinae

Fig。 15 Danainae

Fig. 16 Satyrinae

Fig。 17 Nymphalinae

Fig. 18 Libytheinae

Fig. I9 Riodininae

Fig. 20 Lycaeninae 


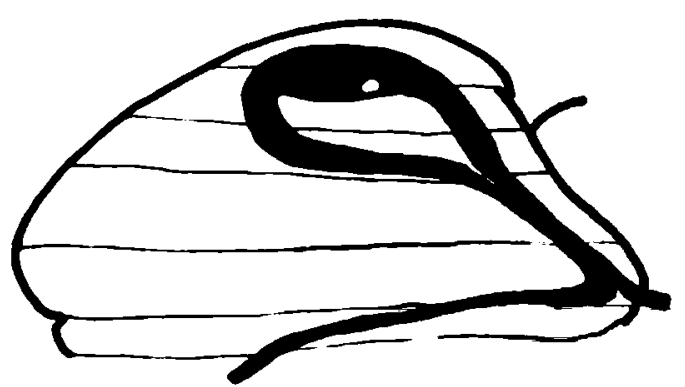

13. Pieris protodice

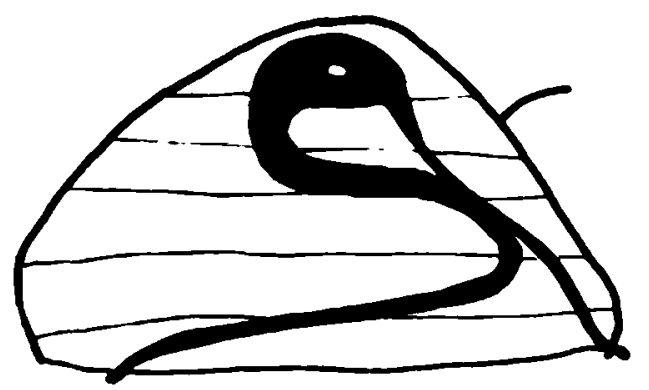

14. Colias caesonia

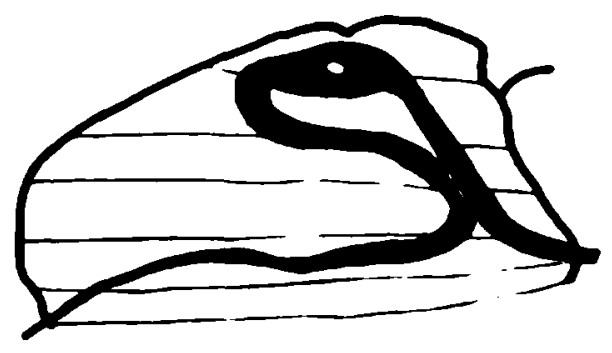

15. Danaus gilippus

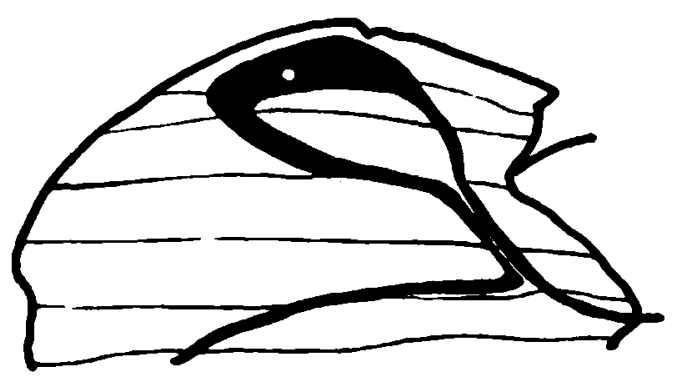

16. Euptychia henshawi

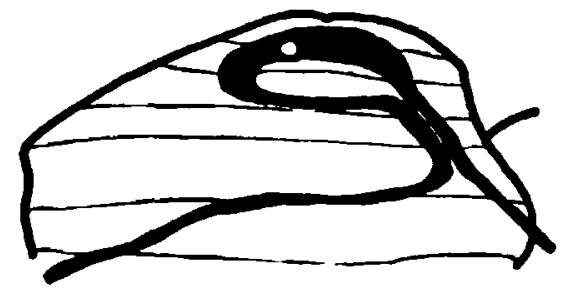

17. Vanessa cardui

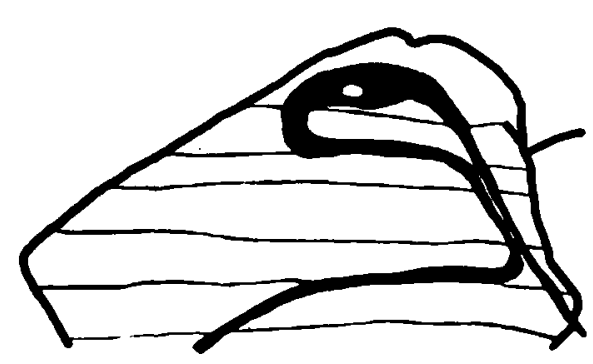

18. Libytheana bachmaniı

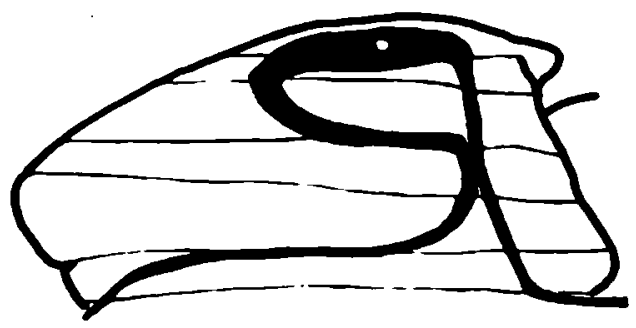

19. Hypaurot!s crysalus

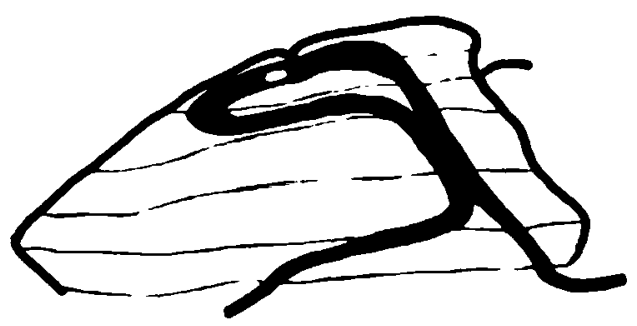

20. Apodenira mormo 

EXPLANATION OF FIGURES

Fig. 21 Dendrogram showing general association of sone lepidopteran superfamilies based on aortal and chamber monphology。 
Higher Moths

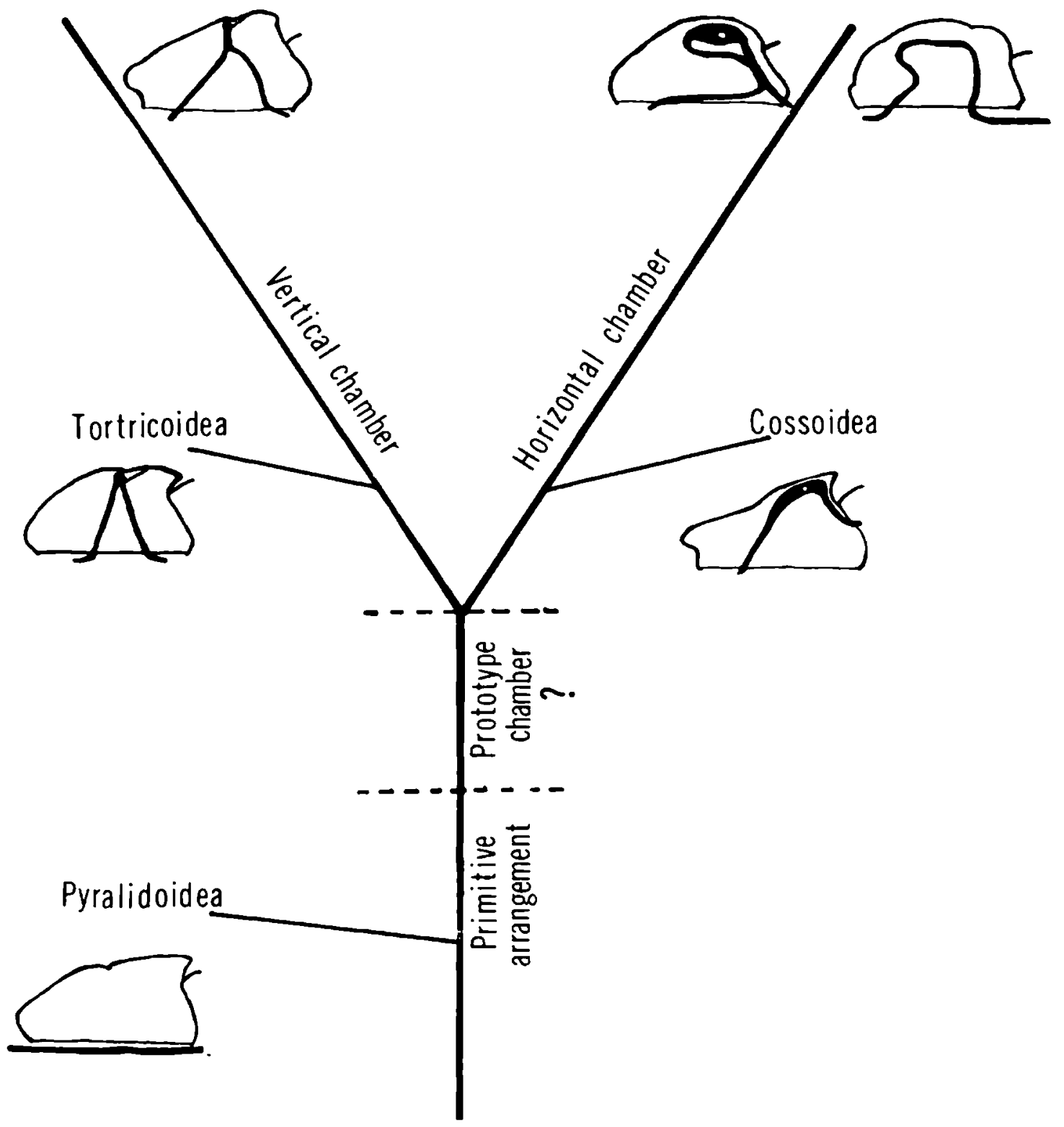

Rhopalocera 